p-ISSN. 2086-9029

e-ISSN. 2654-5675

Vol. 21 No. 1, HIm. 1-124, Juni 2019

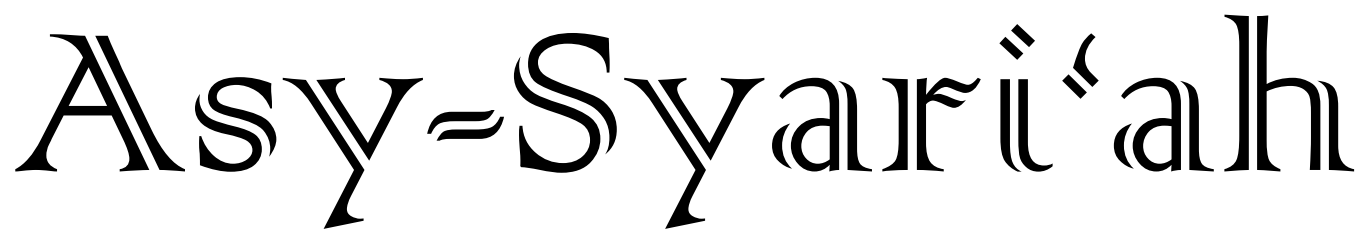

- Islam Nusantara's Perspective on Justice in Polygamy

Beni Ahmad Saebani

- Konstruksi Wakaf Secara Fikih

$(17-30)$ Jaenudin

- Pendekatan Maqashid Syari'ah dalam Praktik Pembiayaan di Koperasi Peternak Sapi Bandung Utara (KPSBU) Lembang Ade Iskandar Nasution

- Kaidah-Kaidah Islam Menjawab Permasalahan Sosial dan Ekonomi Umat

Neneng Hasanah dan Hamzah

- Inovasi Penyaluran Dana Zakat Pada Program Pemberdayaan di Lembaga Amil Zakat

Iw an Setiawan

- Perspektif Siyasah Dusturiyah atas Hak Politik Perempuan dalam Musrembang Kota Bogor

Erma Yulianis

- $\quad$ SBSN PBS, dan SUKRI sebagai Instrumen Pemerintah dalam

Pembiayaan APBN dan Investasi Masyarakat

Suteja Wira Dana Kusuma \& Nisa Dely Amalia

- Partisipasi Politik Kaum Perempuan berdasarkan Pandangan

Fatima Mernissi dan Yusuf Qardhawi

Gayatri Belina Jourdy

FACULTY OF SHARIA AND LAW

STATE ISLAMIC UNIVERSITY SUNAN GUNUNG DJATI BANDUNG-INDONESIA IN COLLABORATION WITH ASOSIASI SARJANA SYARIAH INDONESIA 


\section{Asy-Syari'ah}

\section{Volume 21, Number 1, 2019}

\section{EDITOR-IN-CHIEF}

Ine Fauzia

\section{EDITORIAL BOARD}

Sofyan al-Hakim, UIN Sunan Gunung Djati Bandung, Indonesia Deni Kamaludin Yusup, UIN Sunan Gunung Djati Bandung, Indonesia Meria Utama, Fakultas Hukum Univrsitas Sriwijaya, Indonesia Dewi Mayaningsih, UIN Sunan Gunung Djati Bandung, Indonesia Andrey Sujatmiko, Fakultas Hukum Universitas Trisakti, Jakarta, Indonesia Hetty Hassanah, Universitas Komputer Indonesia, Indonesia

\section{PEER-REVIEWERS}

Muhammad Irfan Helmy, IAIN Salatiga, Semarang, Indonesia Ahmad Ali Nurdin, UIN Sunan Gunung Djati Bandung Tajul Arifin, UIN Sunan Gunun Djati Bandung, Indonesia Mohamad Anton Athoillah, UIN Sunan Gunung Djati Bandung, Indonesia Mrs. Renny Supriyatni, Universitas Padjadjaran, Indonesia Ahmad Tholabi Karlie, UIN Syarif Hidayatullah Jakarta, Indonesia Ija Suntana, UIN Sunan Gunung Djati Bandung, Indonesia Zezen Zaenal Mutaqin, University of California, Los Angeles, United States Ahmad Fathonih, UIN Sunan Gunung Djati Bandung, Indonesia Rahman Syamsuddin, Universitas Islam Negeri Alauddin Makassar, Indonesia

\section{PROOFREADER/DESIGN COVER}

Nanang Sungkawa

\section{LAYOUT EDITOR}

Opik Rozikin

Asy-Syari' ah has been accredited based on the determination of Director General of Research and Development Strengthening, Ministry of Research, Technology and Higher Education of Republic of Indonesia, No. 14/E/KPT/2019 (valid until 2023). 


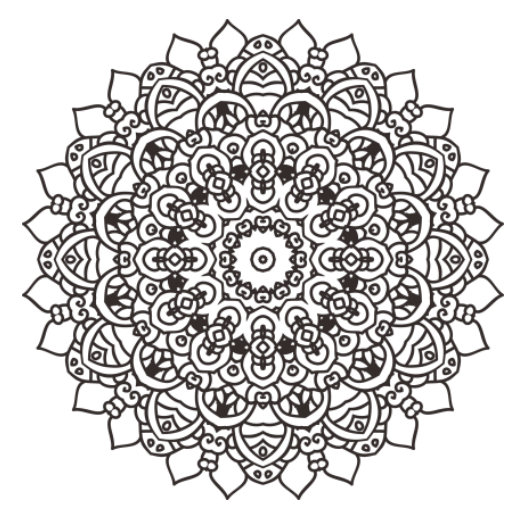

\title{
SBSN PBS, dan SUKRI SEBAGAI INSTRUMEN PEMERINTAH DALAM PEMBIAYAAN APBN DAN INVESTASI MASYARAKAT
}

\author{
Suteja Wira Dana Kusuma dan Nisa Dely Amalia \\ Fakultas Syariah dan Hukum UIN Sunan Gunung Djati Bandung \\ Email : suteja.wiradanakusuma@gmail.com
}

\begin{abstract}
The Sharia capital market is currently growing rapidly in the Indonesian economy. One of the instruments, namely sukuk, is being aggressively fulfilling government needs. Sukuk is widely used as a means of financing the APBN for infrastructure development. In addition, sukuk is also used as a means of investment by the community. Sukuk is the safest investment among investors because it is guaranteed by the government.
\end{abstract}

Keywords: sukuk, Islamic capital market, state budget financing, community investment 
92 |Asy-Syari'ah Vol. 21 No. 1, Juli 2019

Abstrak: Pasar modal Syariah saat ini sedang berkembang pesat di perekonomi Indonesia. Salah satu instrumennya yaitu sukuk sedang gencar dalam memenuhi kebutuhan pemerintah. Sukuk banyak dijadikan sebagai sarana pembiayaan APBN untuk pembangunan infrastruktur. Selain itu, sukuk juga dijadikan sebagai sarana investasi oleh masyarakat. Sukuk adalah investasi paling aman dikalangan para investor karena dijamin oleh pemerintah.

Kata Kunci: sukuk, pasar modal syariah, pembiayaan APBN, investasi masyarakat 


\section{Pendahuluan}

Pertumbuhan dan perkembangan pasar modal di Indonesia saat ini terbilang sangat baik, khususnya bagi pasar modal syariah di Indonesia saat ini menunjukkan tren pertumbuhan yang positif. Tren pertumbuhan positif tersebut terjadi pada tahun 2012 sampai dengan tahun 2017. Tahun 2017, bahkan, merupakan puncak pertumbuhan pasar modal syariah jika dibandingkan dengan dua tahun sebelumnya, yakni dengan pertumbuhan sebesar $43.52 \% .^{1}$

Pasar modal syariah merupakan jawaban atas keraguan masyarakat muslim yang ingin menginvetasikan dananya. Pasar Modal Syariah dianggap tidak bersalahan dengan prinsip-prinsip syariah seperti riba (system bunga), maysir (perjudian), gharar (ketidakpastian) dan lain sebagainya. ${ }^{2}$ Pasar Modal Syariah itu sendiri terdapat beberapa instrumen yaitu meliputi saham syariah, obligasi syariah (sukuk) dan reksadana syariah yang dimana instrumen tersebut sudah mengeluarkan banyak produk yang diminati masyarakat dan berpengaruh baik dalam pertembuhan ekonomi lebih dari 10 tahun terakhir.

Saat ini pasar modal merupakan unsur penting bagi suatu negara. Ketika negara membutuhkan dana tambahan dalam pembangunan, maka negara dapat menerbitkan obligasi atau surat utang dan menjualnya kepada masyarakat melalui pasar modal. Selaiknya pasar pada umumnya maka pasar modal akan mempertemukan pihak yang memerlukan dan pihak yang memiliki kelebihan dana. ${ }^{3}$

Instrumen pasar modal syariah yang akan dibahas di sini adalah Obligasi Syariah yang diantaranya terdiri dari Surat Berharga Syariah Negara-Project Based Sukuk dan Sukuk Ritel yang meliputi pengertian, sejarah, dan kontribusi terhadap pembangunan infrastruktur di Indonesia.

Penelitian ini menggunakan metode deskriptif-kuantitatif dengan sumber data utama dari data sekunder yang sudah dipublikasi secara umum seperti statistik sukuk syariah dan statistik sukuk ritel Indonesia. Data-data tersebut tidak memerlukan uji validitas, karena data-data tersebut merupakan data yang dikeluarkan oleh pihak berwenang, seperti Otoritas Jasa Keuangan, Kementerian Keuangan dan Bank INdo

\section{Sejarah dan Perkembangan Sukuk Di Indonesia}

Secara etimologi Sukuk berasal dari Bahasa arab yang merupakan bentuk jamak (plural) dari kata "shakk" yang memiliki arti dokumen/lembaran kontrak yang serupa dengan sertifikat atau note. ${ }^{4}$ Secara praktis Sukuk berarti merupakan bukti atas kepemilikan terhadap aset yang menjadi dasar penerbitan Sukuk.

\footnotetext{
${ }^{1}$ Otoritas Jasa Keuangan, Kontribusi Investor Retail Di Pasar Modal Syariah Indonesia, 2017, hlm. 10.

2 Budi Setiawan, "Perbandingan Kinerja Pasar Modal Syariah Dan Konvensional : Suatu Kajian Empiris Pada Pasar Modal Indonesia," Jurnal Ilmiah Ekonomi Global Masa Kini 8 (1), no. Juli (2017), hlm. 35

${ }^{3}$ Yenni Samri Juliati Nasution, "Peranan Pasar Modal Dalam Perekonomian Negara," Journal HUMAN FALAH 2, no. 1 (2015): hlm. 95.

${ }^{4}$ Prasetyo, Y., "Hukum Investasi dan Pasar Modal Syariah", (Bandung: Minna Publishing. 2007) hlm.97
} 
Sukuk atau dikenal dengan surat utang syariah berdasarkan Fatwa DSN MUI Tahun 2002, didefinisikan sebagai :

"Suatu surat berharga jangka panjang berdasarkan prinsip syariah yang dikeluarkan emiten kepada pemegang obligasi syariah yang mewajibkan emiten membayar pendapatan kepada pemegang obligasi syariah berupa bagi hasil margin atau fee, serta membayar kembali dana obligasi saat jatuh tempo" ${ }^{5}$.

Adapun pengertian Sukuk menurut Peraturan Otoritas Jasa Keuangan adalah :

"Sukuk adalah Efek Syariah berupa sertifikat atau bukti kepemilikan yang bernilai sama dan mewakili bagian yang tidak terpisahkan atau tidak terbagi (syuyu'l undivided share), atas aset yang mendasarinya". ${ }^{6}$

Penggunaan istilah sukuk ini dapat lebih diterima untuk menggantikan istilah Obligasi Syariah yang terkadang masih mengandung makna ribawi,sebab ada yang berpendapat bahwa Obligasi (surat utang) tidak mungkin bisa dibuat Syariah jika mendapatkan imbalan.

Jenis Sukuk jika didasarkan pada pihak yang menerbitkannya dapat terbagi menjadi dua, yakni (1) Sukuk Korporasi dan (2) Sukuk Negara (SBSN). Sukuk Korporasi adalah sukuk yang kewenangan penerbitannya ada di perusahaan-perusahaan dengan berbagai jenis akad7, sedangkan Sukuk Negara kewenangan penerbitannya ada pada Pemerintah Republik Indonesia melalui Kementerian Keuangan, yang kemudian lebih dikenal dengan Surat Berharga Syariah Negara (SBSN). ${ }^{8}$

Hadirnya Fatwa DSN MUI tentang Sukuk membuka peluang bagi dunia usaha untuk mendapatkan sumber dana baru. Sukuk Korporasi yang pertama kali terbit adalah pada Tahun 2002 oleh PT. Indosat dengan PT. AAA Sekuritas sebagai penjamin emisinya. Pada periode tersebut, sesuai dengan Fatwa Dewan Syariah MUI, akad yang digunakan adalah akad mudharabah. Langkah PT Indosat ini kemudian diikuti oleh perusahaanperusahaan lain seperti PT. Berlian Laju Tangker, PT. Bank Bukopin Syariah, PT. Bank Muamalat, PT. Ciliandra Perkasa, dan PT. Bank Syariah Mandiri. ${ }^{9}$

Perkembangan Sukuk Korporasi berikutnya, sesuai dengan perkembangan Fatwa Dewan Syariah MUI, adalah berkembangnya akad ijarah. Akad ijarah pertama kali digunakan di tahun 2004. ${ }^{10}$ Akad ljarah menjadi lebih banyak digunakan karena mampu memberikan pengembalian keuntungan yang tetap dan pasti jika dibandingkan dengan akad mudharabah, hal ini sejalan dengan sistem perbankan konvensional, dimana biasanya suku bunga tetap lebih diminati dibandingkan dengan suku bunga mengambang. ${ }^{11}$

\footnotetext{
${ }^{5}$ Dewan Syariah Nasional., "Obligasi Syariah", Jakarta, 2002.

${ }^{6}$ Otoritas Jasa Keuangan, "PENERBITAN DAN PERSYARATAN SUKUK," 2015, hlm. 2.

${ }^{7}$ Menurut Nibra Hoesen dalam Iskandar Mirza akad dapat diartikan gabungan atau penyatuan dari penawan (ijab) dan penerimaan (qabul). HIm. 248

${ }^{8}$ Prasetyo, Y., "Hukum Investasi dan Pasar Modal Syariah", Bandung: Minna Publishing. 2007:100.

${ }^{9} \mathrm{Ibid}, \mathrm{hlm} .100$

${ }^{10} \mathrm{lbid}$

${ }^{11}$ Melis, "Perkembangan Sukuk Di Indonesia, Malaysia, Dan Dunia," Economica Sharia 2, no. 2017 (2017), hlm. 79.
} 
Perkembangan Sukuk Korporasi sejak dari tahun 2002 menunjukkan tren yang positif sampai dengan tahun 2018. Berikut adalah Data Sukuk Korporasi dari tahun 2002 sampai dengan 2018. Berbagai perusahaan bermunculan menjadikan Sukuk sebagai salah satu pilihan dalam mendapatkan dana baru. Di tahun 2019 saja sudah ada sebanyak 206 emisi yang dapat dijadikan pilihan untuk investasi. Berikut adalah data OJK mengenai Emisi SUkuk dan Sukuk Outstanding dari tahun 2002 s.d. tahun 2018 :

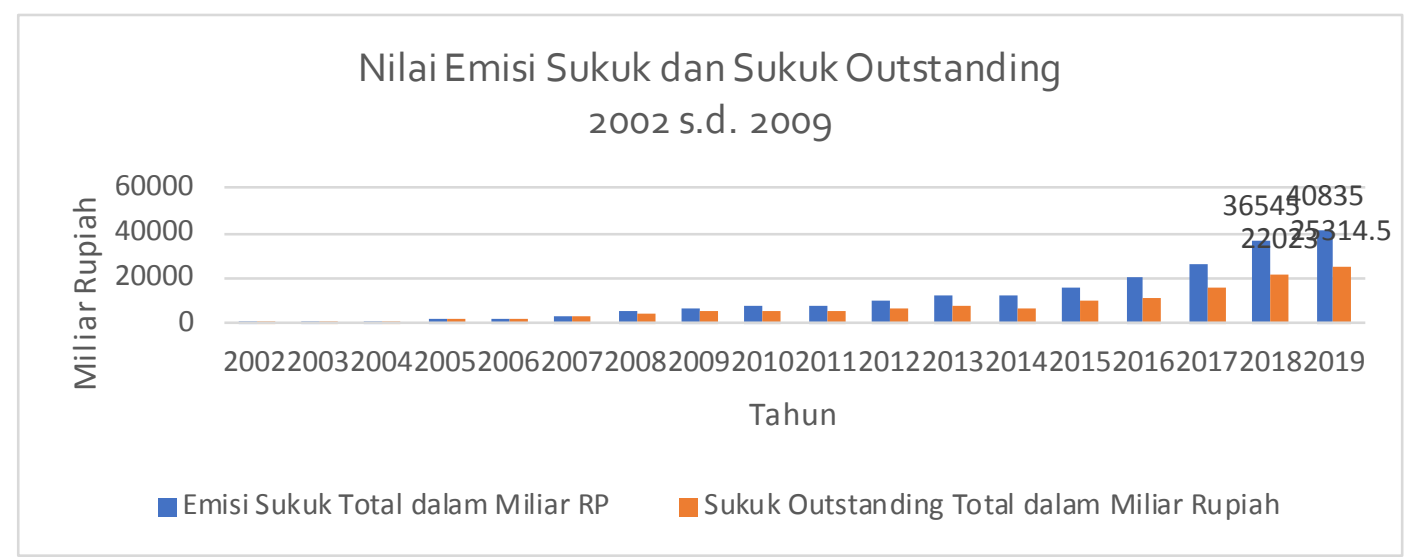

sumber: Statistik Sukuk Syariah 2002-2019. ${ }^{12}$

Sementara itu, Sukuk Negara atau SBSN pertama kali diterbitkan oleh pemerintah pada tahun 2008, setelah Rancangan Undang-Undangan (RUU) Surat Berharga Syariah Negara (SBSN) disahkan menjadi Undang-Undang pada saat sidang paripurna DPR RI di Gedung DPR Jakarta pada tanggal 9 April 2008. Pembahasan tentang RUU SBSN ini telah berlangsung sejak lama, yaitu sejak tahun $2005 .{ }^{13}$

Undang-Undang SBSN tahun 2008 menyatakan bahwa SBSN merupakan salah satu instrumen keuangan yang tidak hanya mampu menjadi alternatif sumber dana dalam pembangunan Indonesia, namun juga sesuai dengan nilai ekonomi, sosial dan budaya masyarakat Indonesia pada umumnya. ${ }^{14}$ Penggunaan prinsip-prinsip syariah dijadikan syarat utama berjalannya program SBSN. ${ }^{15}$

Berikut beberapa jenis-jenis Sukuk Negara yang diterbitkan di Indonesia :

\section{IFR (Islamic Fixed Rate)}

Kementerian Keuangan pada 26 Agustus 2008 telah menerbitkan Surat Berharga Syariah Negara (Sukuk Negara) di pasar keuangan untuk pertama kalinya, Inilah jenis SBSN yang pertama kali diterbitkan, yaitu IFR (Islamic Fixed Rate). Akad yang diguna-

\footnotetext{
${ }^{12}$ Otoritas Jasa Keuangan, "Statistik Pasar Modal Syariah," 2013.

${ }^{13}$ Hariyanto, Eri., "Mengenal Sukuk Negara: Instrumen Pembiayaan APBN dan Sarana Investasi Masyarakat"., 2017, hlm. 9.

${ }^{14}$ Pemerintah Republik Indonesia., "UU. No. 19 tahun 2008 tentang Surat Berharga Syariah Negara"., 2008:1

${ }^{15}$ Ibid, hlm. 2
} 
kannya yaitu ijarah and sales leased back. IFR dijual kepada investor institusi melalui lelang dan private placement dalam jangka waktu di atas 1 tahun

\section{Sukuk Ritel (Sukri)}

Sukuk Ritel pertama kali diterbitkan pada tahun 2009, pemerintah memberikan kesempatan kepada Warga Negara Indonesia untuk berinvestasi dengan berupa Sukuk Ritel (SUKRI). Penerbitan Sukuk Ritel ini dilakukan untuk meraih pasar modal perseorangan atau individu. Sukuk ditawarkan kepada investor individu melalui agen penjual dengan pembeliaan minimal 5 juta Rupiah.

\section{Sukuk Valas}

Dalam rangka berpartisipasi dalam pengembangan pasar keuangan internasional, selanjutnya Pemerintah menerbitkan Sukuk Valas diterbitkan dalam pasar internasional dalam mata uang USD, melalui penjualan Joint Lead Manager (JLM). Pertama kali diterbitkan pada 2009 yaitu denganm seri SNl14 yang telah jatuh tempo pada tahun 2014 .

\section{Sukuk Dana Haji Indonesia ( SDHI)}

Pada tanggal 22 April 2009, Kementerian Agama melakukan kesepakatan untuk menempatkan Dana Haji dan Dana Abadi Umat secara terencana dalam sukuk negara. Saehingga pada bulan Mei tahu 2009 kembali Pemerintah menerbitkan SBSN dengan tipe baru, yaitu Sukuk Dana Haji Indonesia ( SDHI).

\section{Surat Pembendaharaan Negara Syariah}

Pada tahun 2011, Pemerintah menerbitkan Surat Pembendaharaan Negara Syariah (SPNS) dijual kepada investor institusi melalui lelang dan private placement dengan mata uang rupiah. SPNS adalah termasuk SBSN jangka pendek karena jangka waktu maksimum untuk SPNS adalah 1 tahun, dengan imbalan berupa diskonto. Akad yang digunakan dalam penerbitannya adalah ijarah sale and leased back.

\section{Projek Base Sukuk}

Pada tahun 2013, Pemerintah menerbitkan SBSN tipe yang baru, yaitu Projek Base Sukuk (PBS) dijual kepada investor institusi melalui lelang dan private placement, menggunakan underlying berupa proyek maupun kegiatan APBN. Imbalan SBSN PBS berupa kupon yang bersifat fixed dan dibayarkan setiap 6 bulan sekali dengan jenis mata uang Rupiah.

\section{Sukuk Tabungan}

Pada September 2016 diluncurkan Sukuk Tabungan. Sukuk Tabungan ini dijual kepada investor individu WNI dengan nominal Rpı juta rupiah yang dijual melalui Agen Penjual dengan pembelian minimal Rp2 juta Rupiah. Sukuk Tabungan tidak bisa diperdagangkan, namun memiliki fasilitas early redemption.

Hadirnya Sukuk Negara dan Sukuk Korporasi merupakan salah satu sumber pembiayaan bagi para emiten. Penerapan prinsip syariah menjadi syarat wajib penyelengga- 
Suteja Wira Dana Kusuma dan Nisa Dely Amalia, SBSN PBS, dan SUKRI Sebagai Instrumen...| 97

raan pengadaan Sukuk ini, hadirnya Fatwa DSN MUI, RUU SBSN, Peraturan OJK merupakan jaminan atas pelaksanaan sukuk dan jaminan atas penerapan prinsip-prinsip syariah yang membedakannya dengan obligasi maupun surat utang negara.

\section{Peran SBSN-Project Based Sukuk dan Sukuk Ritel dalam Pembangunan Infrastruktur Nasional}

Kebutuhan akan pembangunan infrastruktur di Indonesia sangatlah besar. Seiring dengan kebutuhan infrastruktur yang semakin besar, maka kebutuhan akan alokasi dana untuk infrastruktur juga ikut meningkat. Pada tahun-tahun sebelumnya, meskipun persentase terus meningkat, alokasi dana APBN untuk belum mencapai angka ideal, yakni sebesar $20 \%$ dari jumlah total APBN. ${ }^{16}$

Genjotan yang dilakukan pemerintah antara lain adalah dengan menggalakkan opsi pembiayaan lain. Penerbitan sukuk negara ini merupakan upaya pemerintah untuk memperoleh sumber pembiayaan baru terutama dari sektor keuangan syariah domestic maupun global yang berkembang pesat dalam sepuluh tahun terakhir. Sukuk secara global telah berkembang sejak tahun 1992 dan diterbitkan oleh perusahaan dari Amerika Serikat yaitu General Electric.

Sebagai instrument keuangan yang berlandaskan pada prinsip prinsip keuangan Islam, sukuk negara memiliki beberapa karakteristik yang berbeda bila dibandingkan dengan surat utang negara (SUN) atau obligasi konvensional lainnya. Perbedaan tersebut diantaranya adalah dalam penerbitan Sukuk Negara selalu diperlukan pernyataan kesesuaian syariah dari lembaga yang berwenang dalam bidang tersebut yaitu Dewan Syariah Nasional Majelis Ulama Indonesia (DSN-MUI).

Pernyataan tersebut memberikan penjelasan bahwa seluruh tahapan transaksi dalam penerbitan Sukuk Negara telah sesuai dengan kaidah keuangan islam. Aspek lain yang membedakan adalah perlunya asset yang ditransaksikan dalam setiap penerbitan sukuk negara. Hal ini berbeda dengan SUN yang merupakan surat pernyataan utang, Sukuk Negara merupakan surat pernyataan untuk berinvestasi dalam asset yang ditransaksikan pada sukuk negara. Dengan begitu pemegang sukuk negara adalah investor yang memiliki hak yang tidak terbagikan atas asset yang di transaksikan dalam sukuk negara. Asset yang dimaksud adalah berupa barang dan jasa yang memenuhi kriteria syariah. Dua jenis produk Sukuk Negara yang diperdagangkan saat ini antara lain adalah Sukri (sukuk ritel) dan Project Based Sukuk (PBS)

Sukri sejak diterbitkan pertama kali di tahun 2008, memiliki imbal balik yang cukup tinggi, dan selalu lebih tinggi jika dibandingkan dengan nilai inflasi. Imbal balik tertinggi tercatat ada pada penerbitan pertama sebesar $12 \%$, sementera itu penerbitan Sukri terbesar adai di tahun 2016, dengan nilai penerbitan mencapai Rp. 31.50 triliun. Berikut adalah kemajuan sukuk ritel dari tahun 2009:

\footnotetext{
${ }^{16}$ Haryanto, Eri. "Peluang Pembiayaan Infrastruktur Melalui Sukuk Negara," 2013, hlm. 1.
} 
Tabel 1.1

Perkembangan Sukuk Ritel di Indonesia ${ }^{17}$

\begin{tabular}{cccccc}
\hline $\begin{array}{c}\text { Nomer } \\
\text { Seri }\end{array}$ & $\begin{array}{c}\text { Tahun } \\
\text { Terbit }\end{array}$ & $\begin{array}{c}\text { Tanggal Jatuh } \\
\text { Tempo }\end{array}$ & $\begin{array}{c}\text { Jangka } \\
\text { Waktu }\end{array}$ & $\begin{array}{c}\text { Imbal } \\
\text { Hasil }\end{array}$ & Nilai \\
\hline 001 & 2009 & 25 Februari 2012 & 3 tahun & 12,00\% & Rp 5,55 triliun \\
\hline 002 & 2010 & 10 Februari 2013 & 3 tahun & $8,70 \%$ & Rp 8,00 triliun \\
\hline 003 & 2011 & 23 Februari 2014 & 3 tahun & $8,15 \%$ & Rp 7,34 triliun \\
\hline 004 & 2012 & 21 September 2015 & 3,5 tahun & $6,25 \%$ & Rp 13,61 triliun \\
\hline 005 & 2013 & 27 Februari 2016 & 3 tahun & $6,00 \%$ & Rp 14,96 triliun \\
\hline 006 & 2014 & 05 Maret 2017 & 3 tahun & $8,75 \%$ & Rp 19,32 triliun \\
\hline 007 & 2015 & 11 Maret 2018 & 3 tahun & $8,25 \%$ & Rp 21,96 triliun \\
\hline 008 & 2016 & 10 Maret 2019 & 3 tahun & $8,30 \%$ & Rp 31,50 triliun \\
\hline 009 & 2017 & 10 Maret 2020 & 3 tahun & $6,90 \%$ & Rp 14,04 triliun \\
\hline 010 & 2018 & 10 Maret 2021 & 3 tahun & $5,90 \%$ & Rp 8,43 triliun \\
\hline
\end{tabular}

Penerbitan Sukuk Negara Ritel telah mencatatkan sukses baik dari sisi kontribusi terhadap pembiayaan defisit APBN maupun dari pencapaian target investor. Namun demikian, pemerintah melihat sisi-sisi yang dapat lebih dikembangkan dari penerbitan instrumen investasi untuk investor ritel dengan melihat catatan-catatan dari penerbitan Sukuk Negara Ritel. Beberapa catatan tersebut diantaranya adalah investor Sukuk Negara Ritel ternyata masyarakat Indonesia dengan kemampuan ekonomi menengah ke atas. Hal ini terbukti dari data penerbitan SR-008 bahwa mayoritas investornya $(37,7 \%)$ yang berprofesi sebagai wiraswasta atau pegawai dari institusi swasta berinvestasi pada kisaran 100 juta hingga 600 juta rupiah.

Selain itu Sukuk Negara Ritel juga dapat dikatakan sebagai instrumen investasi yang menguntungkan karena imbal hasil yang diberikan biasanya lebih tinggi dari bunga deposito bank-bank BUMN. Pajak untuk imbalannya juga dikenakan lebih rendah dari deposito, yaitu PPh final sebesar 15\%. Keuntungan lainnya imbalan Sukuk Negara Ritel dibayar setiap bulan, sehingga manfaatnya dapat dinikmati oleh investor secara pasti. Di pasar sekunder, harga Sukuk Negara Ritel biasanya berada pada harga premium (di atas nilai pada saat diterbitkan), hal ini tentu menjadi keuntungan lain bagi investor yang ingin melepas Sukuk-nya di pasar sekunder.

Pembiayaan infrastruktur melalui penerbitan Sukuk Negara telah dilaksanakan sejak tahun 2013 yaitu ketika diterbitkannya Sukuk Negara dengan seri Project Based Sukuk (PBS). Saat ini porsi penerbitan sukuk negara untuk pembiayaan infrastruktur terus mengalami peningkatan. Hal ini seiring dengan semakin banyaknya kementerian/lembaga yang memanfaatkan penerbitan Sukuk Negara untuk pembiayaan proyek. Meningkatnya peran sukuk negara dalam pembiayaan infrastruktur, memberi ruang

${ }^{17}$ Rizal Yaya and Ekta Sofiyana, "Pengaruh Sukuk Ritel Pemerintah Terhadap Penghimpunan Dana Pihak Ketiga Bank Syariah," Media Riset Akuntansi, Auditing \& Informasi 18, no. 2 (2018): 157, https://doi.org/10.25105/mraai.v18i2.3096. 
fiscal bagi pemerintah untuk lebih banyak lagi membangun infrastruktur. Dengan demikian, sukuk negara dapat menjadi salah satu solusi pembiayaan APBN terutama untuk pembiayaan infrastruktur di Indonesia.

Jenis Sukuk Negara Project Based Sukuk terbagi atas dua jenis, yakni : (1) Project Underlying Sukuk (PUS) dan (2) Project Financing Sukuk (PFS). Ada beberapa perbedaan mendasar pada dua jenis sukuk ini, seperti yang diungkapkan presentasi "Peran Sukuk dalam Pembiayaan Pembangunan Berkelanjutan", berikut adalah pembeda antara PUS dan PFS :

\section{Tabel 1.2}

\begin{tabular}{|c|c|c|}
\hline Dimensi & Project Underlying Sukuk & Project Financing Sukuk \\
\hline $\begin{array}{l}\text { Obyek } \\
\text { Pembiayaan }\end{array}$ & $\begin{array}{l}\text { - kegiatan (Belanja Modal } \\
\text { untuk pembangunan fisik, } \\
\text { Rupiah Murni) dalam APBN } \\
\text { tahun berjalan. }\end{array}$ & $\begin{array}{l}\text { - proyek infrastruktur yang di } \\
\text { earmarked dengan SBSN. }\end{array}$ \\
\hline Proses & - ditetapkan $\quad$ Menteri & - ditetapkan bersama-sama \\
\hline Penetapan & $\begin{array}{l}\text { Keuangan setelah UU APBN } \\
\text { disahkan, sehingga tidak } \\
\text { mempengaruhi besaran } \\
\text { defisit }\end{array}$ & $\begin{array}{l}\text { Pemerintah dan DPR dalam pem- } \\
\text { bahasan UU APBN, karena } \\
\text { besarannya dapat mempengaruhi } \\
\text { besaran defisit APBN. }\end{array}$ \\
\hline $\begin{array}{l}\text { Sifat } \\
\text { Pembiayaan }\end{array}$ & $\begin{array}{l}\text { - masih tetap Rupiah Murni } \\
\text { (RM) dan terbatas hanya } \\
\text { Belanja Modal. }\end{array}$ & $\begin{array}{l}\text { - bukan Rupiah Murni melainkan } \\
\text { SBSN-PBS dan tidak terbatas } \\
\text { pada Belanja Modal. }\end{array}$ \\
\hline $\begin{array}{l}\text { Mekanisme } \\
\text { Penganggaran }\end{array}$ & $\begin{array}{l}\text { - Tidak ada perubahan dalam } \\
\text { sistem penganggaran. }\end{array}$ & $\begin{array}{l}\text { - Ada penyesuaian dalam meka- } \\
\text { nisme penganggaran. }\end{array}$ \\
\hline $\begin{array}{l}\text { Mekanisme } \\
\text { Pembiayaan }\end{array}$ & $\begin{array}{l}\text { - diatur dengan Peraturan } \\
\text { Menteri Keuangan. }\end{array}$ & $\begin{array}{l}\text { - } \text { diatur dengan Peraturan } \\
\text { Pemerintah. }\end{array}$ \\
\hline
\end{tabular}

Seiring berjalannya waktu, dari kedua jenis PBS yang ada, hanya PFS yang berkontribusi dalam pembangunan infrastruktur. Penerbitan PFS sejak tahun 2013 mengalami perkembangan positif baik dalam segi jumlah maupun besaran nilai rupiah. Berikut adalah infrastruktur yang sudah dibiayai oleh skema PFS :

\section{Tabel 1.3}

\section{Pekerjaan dengan dana berasal dari PFS $^{19}$}

\begin{tabular}{llll}
\hline Tahun & Nilai Anggaran & $\begin{array}{c}\text { Institusi Pelaksana } \\
\text { Pekerjaan }\end{array}$ & Pembangunan Infrastruktur \\
\hline 2013 & Rp. 800 juta & $\begin{array}{l}\text { Kementerian } \\
\text { Perhubungan }\end{array}$ & $\begin{array}{l}\text { Rel Kereta Api Jalur Ganda } \\
\text { Cirebon Kroya }\end{array}$ \\
\hline
\end{tabular}

${ }^{18}$ Kementerian Keuangan, "Peran Sukuk Negara Dalam Pembiayaan Pembangunan Berkelanjutan Indonesia Berkomitmen Mengatasi Perubahan Iklim Global," 2018, hlm. 15.

${ }^{19}$ Novia Khairunnisa, "SUKUK DAN PEMBANGUNAN INFRASTRUKTUR DI INDONESIA," 2018, hlm. 69. 


\begin{tabular}{|c|c|c|c|}
\hline \multirow[t]{2}{*}{2014} & \multirow[t]{2}{*}{ Rp. 1.5 triliun } & $\begin{array}{l}\text { Kementerian } \\
\text { Perhubungan }\end{array}$ & $\begin{array}{l}\text { Rel Kereta Api Jalur Ganda } \\
\text { Cirebon-Kroya dan Manggarai- } \\
\text { Jatinegara }\end{array}$ \\
\hline & & Kementerian Agama & - Pembangunan Asrama Haji \\
\hline \multirow[t]{3}{*}{2015} & \multirow[t]{3}{*}{ Rp. 7.1 triliun } & $\begin{array}{l}\text { Kementerian } \\
\text { Perhubungan }\end{array}$ & $\begin{array}{l}\text { - Rel Kereta Api Jakarta, Jawa } \\
\text { Tengah Sumatera }\end{array}$ \\
\hline & & $\begin{array}{l}\text { Kementerian } \\
\text { Pekerjaan Umum }\end{array}$ & $\begin{array}{l}\text { - Jalan dan Jembatan di } \\
\text { beberapa Provinsi }\end{array}$ \\
\hline & & Kementerian Agama & - Infrastruktur Kampus dan KUA \\
\hline \multirow[t]{3}{*}{2016} & \multirow[t]{3}{*}{ Rp. 13.67 triliun } & $\begin{array}{l}\text { Kementerian } \\
\text { Perhubungan }\end{array}$ & $\begin{array}{l}\text { - Rel Kereta Api Jakarta, Jawa } \\
\text { Tengah Sumatera. } \\
\text { - Rel kereta api dan jalur ganda }\end{array}$ \\
\hline & & $\begin{array}{l}\text { Kementerian } \\
\text { Pekerjaan Umum }\end{array}$ & $\begin{array}{l}\text { - Jalan dan Jembatan di } \\
\text { beberapa Provinsi } \\
\text { - Flyover lintas Sumatera }\end{array}$ \\
\hline & & Kementerian Agama & - Infrastruktur Kampus dan KUA \\
\hline \multirow[t]{3}{*}{2017} & \multirow[t]{3}{*}{ Rp. 16.76 triliun } & $\begin{array}{l}\text { Kementerian } \\
\text { Perhubungan }\end{array}$ & $\begin{array}{l}\text { - Elevated Track dan jalur ganda } \\
\text { jabodetabek, Jawa Tengah, } \\
\text { Jawa Timur, Sumatera dan } \\
\text { Sulawesi. }\end{array}$ \\
\hline & & $\begin{array}{l}\text { Kementerian } \\
\text { Pekerjaan Umum }\end{array}$ & $\begin{array}{l}\text { - Flyover, underpass dan } \\
\text { jembatan Sumatera, Jawa, } \\
\text { NTB, Borneo, Sulawesi, Maluku } \\
\text { dan Papua; } \\
\text { - Pengendalian banjir, lava, } \\
\text { drainase perkotaan, keamanan } \\
\text { pesisir, pengelolaan } \\
\text { bendungan, embung dan } \\
\text { penampungan air; }\end{array}$ \\
\hline & & Kementerian Agama & $\begin{array}{l}\text { - } \text { Revitalisasi dan pengembangan } \\
\text { asrama haji dan pusat } \\
\text { rehabilitasi }\end{array}$ \\
\hline
\end{tabular}

Di tahun 2019 sendiri sudah direncanakan akan ada 619 pekerjaan yang akan dilaksanakan melalui jalur SBSN-PBS. Nilai SBSN-PBS 2019 pun lebih besar jika dibandingkan dengan tahun 2018, tahun 2018 pembiayaan proyek mencapai Rp. 22.53 triliun, sementara di tahun 2019 pembiayaan proyek SBSN-PBS mencapai Rp. 28.43 triliun. ${ }^{20}$ Meningkatnya SBSN-PBS tiap tahunnya menunjukkan bahwa, selain meningkatnya komitmen pemerintah atas infrastruktur, namun juga terdapat peningkatan minat investor dalam menanamkan modalnya di SBSN. 
Investor untuk SBSN PBS adalah korporasi dan institusi dan penerbitannya diharuskan dengan metode lelang, sehingga hal ini menutup kemungkinan untuk berinvestasi secara perseorangan. Kementerian Keuangan memberikan pilihan lain agar pihak perseorangan pun dapat ikut berkontribusi dalam pembangunan infrastuktur Indonesia, dengan menghadirkan Sukuk Ritel. ${ }^{21}$ Penerbitan Sukuk Ritel ini dapat diibaratkan sebagai "simbiosis mutualisme" antara pemerintah dan masyarakat, dimana pemerintah mendapatkan dana, sementara masyarakat mendapatkan keuntungan dan infrastruktur baru. $^{22}$

Sukuk Negara dapat di kategorikan sebagai instrumen investasi yang aman karena diterbitkan oleh pemerintah Indonesia melalui Kementerian Keuangan. Investasi ini juga bebas risiko gagal bayar (default) karena diterbitkan oleh pemerintah dan pembayaran pokok investasi maupun imbal hasilnya dijamin dalam Undang-Undang APBN. Selama roda pemerintah masih berjalan, pembayaran pokok investasi dan imbal hasil yang harus dibayarkan kepada para investor telah dianggarkan dalam APBN. Hal ini tentu akan memberi kenyamanan kepada para investor Sukuk Negara.

Dengan demikian, sebetulnya pasar Sukuk Negara dapat lebih dikembangkan lagi baik untuk investor ritel maupun korporasi. Selain itu, berdasarkan masukan masyarakat melalui sosialisasi Sukuk Negara yang dihimpun oleh Direktorat Pembiayaan Syariah, banyak sekali calon investor individu yang mengharapkan agar nilai investasi terendah pada Sukuk Negara Ritel dapat diturunkan sehingga dapat lebih terjangkau oleh para investor pemula.

\section{Kesimpulan}

Sukuk Negara dijadikan sebagai sarana perkembangan ekonomi di Indonesia. Perkembangan sukuk negara ini bisa dilihat dari pemerintah yang menjadikan sukuk sebagai sarana pembiayaan APBN. Sukuk diterbitkan dalam berbagai bentuk jenis, yaitu IFR (Islamic Fixed Rate), Sukuk Ritel (Sukri), Sukuk Valas, Sukuk Dana Haji Indonesia (SDHI), Surat Pembendaharaan Negara Syariah, Projek Base Sukuk, Sukuk Tabungan. Jenis-jenis tersebut mengembankan sektor pertumbuhan dari segi infrastuktur, ekonomi dll.

Selain itu, banyak masyarakat yang tertarik berinvestasi dalam bentuk sukuk dikarenakan dijamin oleh pemerintah. Sukuk ini tidak hanya bisa dimiliki oleh beberapa orang, tetapi oleh setiap kalangan yang berniat untuk membeli sukuk. Untuk kedepannya sukuk akan selalu digunakan dalam setiap sektor perekonomian karena sangat menjanjikan untuk prospek ke depannya.

${ }^{21}$ Direktorat Pembiayaan Syariah and Kementerian Keuangan, "Investasi Syariah Melalui Surat Berharga Syariah Negara ( Sukuk Negara ) Surat Berharga Syariah Negara ( SBSN / Sukuk Negara )," 2017, hlm. 14.

${ }^{22}$ Hariyanto, Eri., "Mengenal Sukuk Negara: Instrumen Pembiayaan APBN dan Sarana Investasi Masyarakat"., 2017, hlm. 92. 
Langkah-langkah yang dapat ditempuh untuk meningkatkan peran project financing sukuk dalam pembiayaan infrastruktur diantaranya yaitu :

Pertama, Meningkatkan pemahaman Kementerian atau lembaga mengenai Project Financing Project. Pembiayaan infrastruktur melalui penerbitan sukuk negara merupakan instrument baru. Selama ini pembiayaan pembangunan infrastruktur dibiayai oleh pengeluaran APBN yang bersumber dari penenrimaan negara atau dibiayai melalui pinjaman langsung dari para lenders. Oleh karena itu, kementrian /lembaga selaku pemilik kegiatan perlu diberikan pemahaman mengenai alternative baru dala pembiayaan infrastruktur. Hal utama yang diharapkan dalah pemahaman bahwa mekanisme pembiayaan infrastruktur melalui penerbitan sukuk negara hamper sama dengan mekanisme pembiayaan lainnya. Langkah yang dapat ditempuh untuk meningkatkan pemahaman kementeran adalah penyelenggara sosialisasi dan edukasi.

Kedua, Menambah struktur sukuk negara berbasis pembiayaan infrastruktur. Saat ini sukuk negara telah diterbitkan dengan berbagai struktur akad. Setiap struktur memiliki keunikan underlying asset yang digunakan. Beberapa jenis underlying yang digunakan adalah barang milik negara, jasa layanan haji, dan pembangunan infrastruktur. Agar lebih banyak lagi pembangunan infrastruktur yang dapat dibiayai dengan penerbitan sukuk negara, maka dalam pengembangan struktur sukuk negara agar mengutamakan penggunaan pembangunan infrastruktur sebagai underlying asset.

Ketiga, Mendorong terciptanya pasar sukuk negara yang aktif dan likuid. Pasar sukuk negara yang aktif dan likuid sangat diperlukan dalam penerbitan sukuk negara dalam jumlah yang besar, sebab dengan kondisi tersebut maka penerbitan sukuk negara akan tetap efien. Kondisi ini akan memungkinkan pemerintah menerbitkan sukuk negara dalam jumlah besar dengan permintaan imbalan yang wajar. Selain itu kondisi pasar yang aktif dan likuid memberi daya Tarik bagi investor karena akan terhindar dari resiko pasar ketika akan menjual atau membeli kembali sukuk negara di pasar sekunder.

\section{DAFTAR PUSTAKA}

Andrian, S. "Pasar Modal Syariah". Jakarta: Sinar Grafika 2011.

Baharudin, A. "Pasar Modal Syariah". Yogyakarta: UII Press 2008

Dewan Syariah Nasional MUI. "Obligasi Syariah", Fatwa DSN MUI Nomor: 32/DSN$\mathrm{MUI} / \mathrm{IX/2002.}$

Direktorat Pembiayaan Syariah and Kementerian Keuangan, "Investasi Syariah Melalui Surat Berharga Syariah Negara ( Sukuk Negara) Surat Berharga Syariah Negara ( SBSN / Sukuk Negara )," 2017, 14.

Hariyanto, Eri. "Peluang Pembiayaan Infrastruktur Melalui Sukuk Negara," 2013, 200911.

Hariyanto, Eri. Mengenal Sukuk Negara Instrumen Pembiayaan APBN dan Sarana Investasi Masyarakat. Yogyakarta : Gava Media. 2017 
Keuangan, Kementerian. "Peran Sukuk Negara Dalam Pembiayaan Pembangunan Berkelanjutan Indonesia Berkomitmen Mengatasi Perubahan Iklim Global," 2018. Khairunnisa, Novia. "SUKUK DAN PEMBANGUNAN INFRASTRUKTUR DI INDONESIA," 2018.

Mirza Iskandar, Keabsahan Akad Jual Beli Multi Level Marketing Dalam Perspektif Teori Hukum Perjanjian Syari'Ah (Nazhâriyyat Al-'Uqûd), Asy-Syari'ah Volume 17 No. 3 Desember 2015.

Melis. "Perkembangan Sukuk Di Indonesia, Malaysia, Dan Dunia." Economica Sharia 2, no. 2017 (2017): 72-84.

Nasution, Yenni Samri Juliati. "Peranan Pasar Modal Dalam Perekonomian Negara." Journal HUMAN FALAH 2, no. 1 (2015): 95-112.

Otoritas Jasa Keuangan. Kontribusi Investor Retail Di Pasar Modal Syariah Indonesia , 2017.

—. "PENERBITAN DAN PERSYARATAN SUKUK," 2015.

_. "Peraturan Otoritas Jasa Keuangan," No.18/POJK.04/2015.

_. "Statistik Pasar Modal Syariah," 2013.

_. "Statistik Pasar Modal Syariah," 2014.

_. "Statistik Pasar Modal Syariah," 2015.

_. "Statistik Pasar Modal Syariah," 2016.

_. "Statistik Pasar Modal Syariah," 2017.

_. "Statistik Pasar Modal Syariah," 2018.

_. "Statistik Pasar Modal Syariah," 2019.

Rizal Yaya and Ekta Sofiyana, "Pengaruh Sukuk Ritel Pemerintah Terhadap Penghimpunan Dana Pihak Ketiga Bank Syariah," Media Riset Akuntansi, Auditing \& Informasi 18, no. 2 (2018): 157, https://doi.org/10. 25105/ mraai. v18i2.3096.

Setiawan, Budi. "Perbandingan Kinerja Pasar Modal Syariah Dan Konvensional : Suatu Kajian Empiris Pada Pasar Modal Indonesia." Jurnal Ilmiah Ekonomi Global Masa Kini 8 (1), no. Juli (2017): 35-40.

Syariah, Direktorat Pembiayaan, and Kementerian Keuangan. "Investasi Syariah Melalui Surat Berharga Syariah Negara ( Sukuk Negara) Surat Berharga Syariah Negara ( SBSN / Sukuk Negara )," 2017.

Pemerintah Republik Indonesia. "Surat Berharga Syariah Negara." Undang-Undang Nomor 19 Tahun 2008 tentang Sertifikat Berharga Syariah Nasional. Lembaran Negara Republik Indonesia Tahun 2008 No. 70

Prasetyo, Y. (2017). Hukum Investasi dan Pasar Modal Syariah. Bandung: Minna Publishing. 
104 | Asy-Syari'ah Vol. 21 No. 1, Juli 2019 
Asy-Syari'ah (P-ISSN : 2086-9029 E-ISSN: 2654-5675) is a periodical scientific journal that publishes various results of studies and research, literature review, and other scientific works whose scope covers the field of Islamic law/sharia, law and society in monodisciplinary, interdisciplinary, and multidisciplinary manners. The journal aims to expand and create innovative concepts, theories, paradigms, perspectives and methodologies in the above said scope. The Journal is published twice a year (june and december) by Faculty of Shariah and Law, Sunan Gunung Djati State Islamic University Bandung in collaboration with Asosiasi Sarjana Syariah Indonesia (ASSYI).

\section{EDITORIAL OFFICE:}

Fakultas Syariah dan Hukum UIN Sunan Gunung Djati Bandung Jl. Raya A.H. Nasution No. 105 Cibiru Kota Bandung, 40614

Tlp/Fax: +022-7802278 Faks. 022-7802278

Website http://journal.uinsgd.ac.id/index.php/asy-syariah/index

E-mail: Jurnalasy-syariah@uinsgd.ac.id 